\title{
Influence of Cissus populnea stem extract on kinetics and thermodynamics of mild steel corrosion in acidic medium
}

\author{
Habibat F. CHAHUL, ${ }^{*}$ David T. ORHEMBA, and Taiwo A. GBADAMOSI \\ Department of Chemistry, Federal University of Agriculture, P.M.B. 2373 Makurdi, Nigeria
}

\begin{abstract}
The inhibition of mild steel corrosion in $1.0 \mathrm{M} \mathrm{HCl}$ and $0.5 \mathrm{M} \mathrm{H}_{2} \mathrm{SO}_{4}$ by Cissus populnea stem extract was investigated using weight loss measurements in the temperature range of $303-333 \mathrm{~K}$. Results from the study revealed that Cissus populnea stem extract inhibited the corrosion of mild steel in both acid media. Inhibition efficiency of the stem extract increased with increase in the extract concentration but decreased with immersion time. The kinetics of the reaction aligned with a first order type. Thermodynamics investigations showed that Cissus populnea extract is adsorbed on the steel surface through physical interactions, and the adsorption process was endothermic and spontaneous. Langmuir, Freundlich and Temkin isotherm models best described the adsorption mechanism of the stem extract on the steel surface.
\end{abstract}

Keywords: corrosion inhibition, Cissus populnea extract, mild steel, kinetics, temperature dependence, corrosion rate.

\section{Introduction}

Most metals are inherently unstable and have the natural tendency to react with their environments to obtain lower energy states by forming their oxides and sulfides. Corrosion is the deterioration of metals/alloys by chemical attack or reaction with the environment. It is a complex problem, which is often difficult to eliminate completely, but it can be controlled by appropriate methods [1]. Steel is particularly used in most structural shapes such as beams, plates, bars, pipes, reaction vessels, tanks etc. Steel materials are very susceptible to attack in aggressive media and happen to be the most commonly exposed alloy in industrial environments hence, posing a great challenge to engineers, scientists and other stakeholders [2].

The use of inhibitors is one of the best options for protecting steel against corrosion. Corrosion inhibitors are substances that, when added to a particular environment, decrease the rate of the environment's attack on metal/alloy. Corrosion inhibitors help to extend the life span of an equipment, prevent system shut downs and failures, avoid product contaminations, prevent loss of heat transfer and preserve an attractive appearance of structural materials.

Corrosion inhibitors decrease or prevent the corrosion of a metal/alloy in an aggressive media by:

i) Adsorption of inhibitor ions/molecules onto the metal surface;

ii) Increasing or decreasing the anodic and/or cathodic reaction on the metal surface;

iii) Decreasing the diffusion rate for reactants to the surface of the metal;

iv) Decreasing the electrical resistance of the metal surface.

Inorganic and organic compounds have been employed and are still being used in the control of corrosion of metals and alloys [3-5]. However, most of these compounds are expensive and toxic. In an attempt to find corrosion inhibitors which are environmentally safe and readily available, attention has been drawn to the use of ecofriendly materials such as extracts from plant parts [6 - 8].

Plant materials are cheap, eco-friendly, readily available and renewable source of materials. Materials obtained from plants are a great source of heterocyclic compounds. The adsorption of these compounds on metal/alloy surfaces have been reported to slow down the corrosion process in metals/alloys [9], hence, recent developments in the area of corrosion mitigation has been on the screening of the extract of different plant parts for their inhibitive properties [8, 10-12]. Alkaloids have been identified as the major chemical constituent of Cissus populnea (CP) stem extract. Other phytochemical compounds are flavonoids, saponins, tannins, cyanogenic and cardiac glycosides, anthraquinones and terpenoids [13, 14].

In a previous study, we reported the inhibitive properties of CP stem extract against the dissolution of aluminum in $0.5 \mathrm{M} \mathrm{HCl}$ [9]. The study showed that $\mathrm{CP}$ stem extract inhibited the dissolution of aluminum in the acid medium. This present study reports on the kinetics and thermodynamics of the corrosion of mild steel in 1.0 $\mathrm{M} \mathrm{HCl}$ and $0.5 \mathrm{H}_{2} \mathrm{SO}_{4}$ in the presence of Cissus populnea stem extract using weight loss measurements.

\section{Experimental}

\subsection{Materials preparation}

Mild steel coupons of dimension $3 \times 2 \times 0.11 \mathrm{~cm}^{2}$ and percentage composition: $\mathrm{Si}-0.03 \%, \mathrm{P}-0.04 \%, \mathrm{~S}-0.04$ $\%, \mathrm{Mn}-0.60 \%$ and the rest Fe, were used for this study. Analar grade reagents were purchased from Emole Chemicals in Makurdi, Nigeria.

\footnotetext{
* Corresponding author. E-mail address:momohbat2007@gmail.com (Habibat F. Chahul).
} 


\subsection{Preparation of Cissus populnea stem extract}

Fresh stems of Cissus populnea plant were procured at North Bank market, Makurdi Local Government Area of Benue State, Nigeria. The stem of the plant was first of all scrapped with the aid of a knife to remove the outer covering. The stem was later shredded using a knife. The shredded plant stem was soaked in hot water for about 15 minutes to allow for easy extraction and then squeezed with hands to remove the extract which was then filtered using a sieve to obtain a chaff free extract. The air-dried extract was blended with an electric blender into fine powder and kept dry in an air-tight container prior to use. Inhibitor test solutions of $0.2 \mathrm{~g} / \mathrm{L}-1.0 \mathrm{~g} / \mathrm{L}$ concentrations were prepared by dissolving $0.05 \mathrm{~g}-0.25 \mathrm{~g} \mathrm{CP}$ extract powder in $250 \mathrm{~mL} 1.0 \mathrm{M} \mathrm{HCl}$ and $0.5 \mathrm{M} \mathrm{H}_{2} \mathrm{SO}_{4}$ respectively [9].

\subsection{Weight loss measurements}

Weight loss measurements were carried out as reported in previous studies [9]. Pre-weighed mild steel coupons were immersed with the aid of glass hooks in duplicates

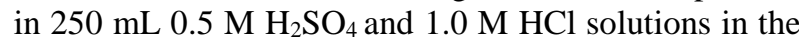
absence and presence $0.2 \mathrm{~g} / \mathrm{L}-1.0 \mathrm{~g} / \mathrm{L} \mathrm{CP}$ stem extract. They were removed at specified time intervals, washed in water, cleaned with ethanol, dried with acetone and reweighed. The average loss in weight was taken as the difference between the initial and final weights of the mild steel. The corrosion rate of the mild steel as a function of time was investigated by carrying out the experiment for $24-168 \mathrm{~h}$. The effect of temperature on the corrosion process of the steel in both the free acid and inhibited solutions was investigated in a similar manner for three hours with the water bath maintained at 303, 313,323 and $333 \mathrm{~K}$ respectively.

Eqs. 1 to 4 were used to calculate the weight loss (g), corrosion rate $\left(\mathrm{g} \cdot \mathrm{h}^{-1} \cdot \mathrm{cm}^{-2}\right)$, inhibition efficiency (IE, \%) and the degree of surface coverage $(\theta)$ respectively.

$$
\begin{aligned}
& \Delta w=w_{2}-w_{1} \\
& C R\left(g h^{-1} \mathrm{~cm}^{-2}\right)=\frac{\Delta w}{A t} \\
& I E_{\exp }=\left(1-\frac{w_{1}}{w_{2}}\right) x 100 \\
& \theta=1-\frac{w_{1}}{w_{2}}
\end{aligned}
$$

where $w_{1}$ and $w_{2}$ are the weight (g) of mild steel with and without the inhibitor, $\Delta w$ is the weight loss of mild steel in time, $\theta$ is the extent of surface coverage of the inhibitor, $A$ is the area of the metal coupon $\left(\mathrm{cm}^{2}\right)$ and $t$ is the immersion period (h) [9].

\section{Results and discussion}

\subsection{Variation of weight loss of mild steel with CP stem extract}

The corrosion rates of mild steel in $0.5 \mathrm{M} \mathrm{H}_{2} \mathrm{SO}_{4}$ and 1.0 $\mathrm{M} \mathrm{HCl}$ solutions were investigated at $0.2 \mathrm{~g} / \mathrm{L}, 0.4 \mathrm{~g} / \mathrm{L}, 0.6$ $\mathrm{g} / \mathrm{L}, 0.8 \mathrm{~g} / \mathrm{L}$ and $1.0 \mathrm{~g} / \mathrm{L} \mathrm{CP}$ stem extract concentrations for $24 \mathrm{~h}$, at room temperature. The results obtained for the variation of the loss in weight of the mild steel with $\mathrm{CP}$ concentration is presented in Figure 1.
It is evident from Figure 1 that the loss in weight of the steel, hence, its corrosion rates in $0.5 \mathrm{M} \mathrm{H}_{2} \mathrm{SO}_{4}$ and 1.0 $\mathrm{M} \mathrm{HCl}$ decreased with increase in the concentration of the stem extract. This suggests that increase in the concentration of $\mathrm{CP}$ stem extract led to a corresponding increase in surface coverage of the adsorbed inhibitor on the steel surface. Increase in surface coverage of an inhibitor on the surface of a metal/alloy has been reported to provide a barrier for the surface of the metal/alloy hence preventing further corrosion in aqueous media [8, 15]. Figure 2 illustrates the trend of IE of CP stem extract as a function of concentration. Inhibition efficiency of the stem extract was observed to increase with the inhibitor concentration signifying the concentration dependent nature of the corrosion inhibition process. This observation is corroborated by other researchers [9, 16]. Figure 2 also reveals that $\mathrm{CP}$ stem extract gave the optimum IE of $84.62 \%$ in $1.0 \mathrm{M} \mathrm{HCl}$ as compared to $72 \%$ in $0.5 \mathrm{M} \mathrm{H}_{2} \mathrm{SO}_{4}$. The higher value of IE in $1.0 \mathrm{M} \mathrm{HCl}$ maybe attributable to the presence of the chloride ions in $\mathrm{HCl}$ which could have improved the adsorption of the organic cations of the inhibitor by forming intermediate bridges between the positively charged metal surface and the positive end of the organic inhibitor $[9,17]$.

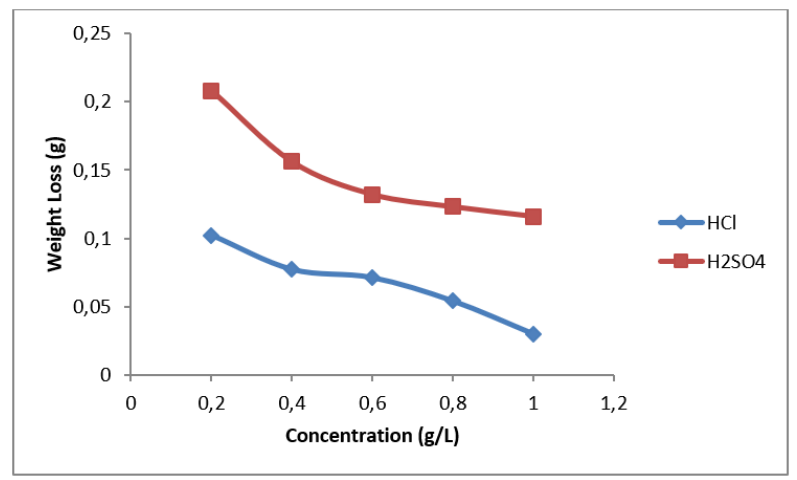

Figure 1. Weight loss of mild steel as a function of various concentrations of $\mathrm{CP}$ in $0.5 \mathrm{M} \mathrm{H}_{2} \mathrm{SO}_{4}$ and $1.0 \mathrm{M} \mathrm{HCl}$.

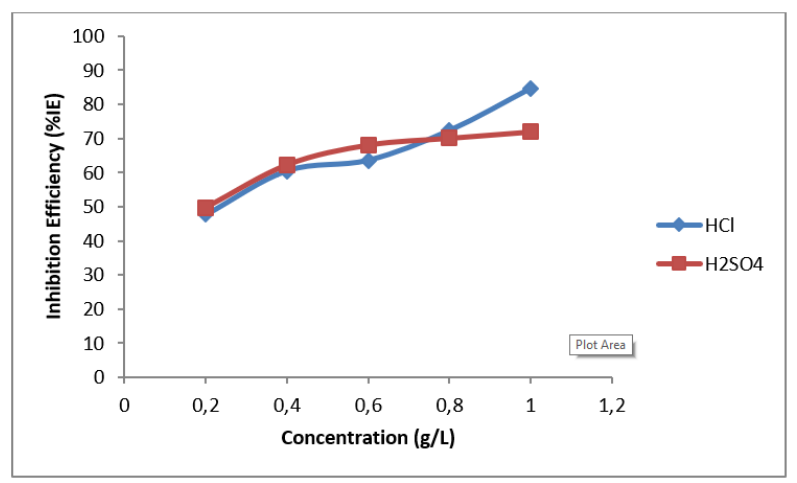

Figure 2. Inhibition efficiency as a function of various concentrations of $\mathrm{CP}$.

\subsection{Variation of weight loss of mild steel with time}

In order to evaluate the effect of time on the corrosion rate of the steel coupons in the selected acid media, the corrosion rate of mild steel in $0.5 \mathrm{M} \mathrm{H}_{2} \mathrm{SO}_{4}$ and $1.0 \mathrm{M}$ $\mathrm{HCl}$ solutions was separately investigated at $24 \mathrm{~h}, 48 \mathrm{~h}$, $72 \mathrm{~h}, 96 \mathrm{~h}$ and $120 \mathrm{~h}$ using CP stem extract concentrations of $0.2 \mathrm{~g} / \mathrm{L}, 0.6 \mathrm{~g} / \mathrm{L}$, and $1.0 \mathrm{~g} / \mathrm{L}$ at room temperature. The results showed that corrosion rates of mild steel in both acid media increased with time, hence increasing the 
magnitude of weight loss of the steel coupons in $0.5 \mathrm{M}$ $\mathrm{H}_{2} \mathrm{SO}_{4}$ and $1.0 \mathrm{M} \mathrm{HCl}$ as illustrated in Figures 3 and 4 respectively. However, the magnitude of the weight loss of the coupons in the inhibited systems in both acid media were less compared to the ones in the free acid solutions (blanks). This shows that $\mathrm{CP}$ stem extract inhibited the corrosion of the steel coupons in both $0.5 \mathrm{M} \mathrm{H}_{2} \mathrm{SO}_{4}$ and 1.0 M HCl solutions.

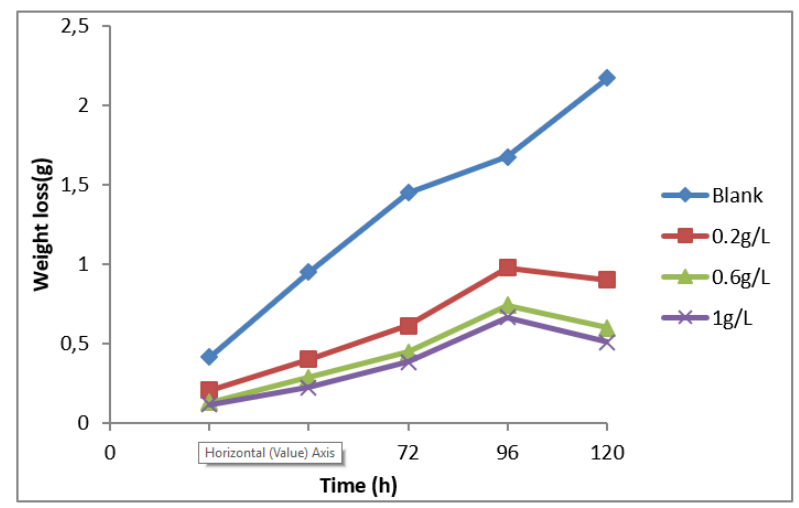

Figure 3. Weight loss of mild steel as a function of immersion time in $0.5 \mathrm{M} \mathrm{H}_{2} \mathrm{SO}_{4}$ in the absence and presence $\mathrm{CP}$ stem extract.

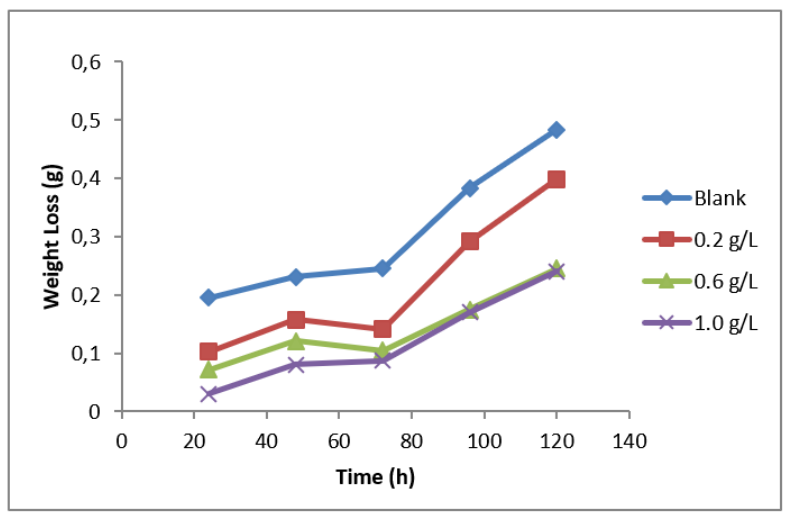

Figure 4. Weight loss of mild steel as a function of immersion time in $1.0 \mathrm{M} \mathrm{HCl}$ in the absence and presence $\mathrm{CP}$ stem extract.

Figures 5 and 6 show the trend in inhibition efficiency of $\mathrm{CP}$ stem extract with immersion time of the steel coupons in $0.5 \mathrm{M} \mathrm{H}_{2} \mathrm{SO}_{4}$ and $1.0 \mathrm{M} \mathrm{HCl}$ solutions respectively. Inhibition efficiency of the $\mathrm{CP}$ was observed to decrease with immersion time in both acid media. Though an optimum inhibition efficiency of $84 \%$ at an inhibitor concentration of $1.0 \mathrm{~g} / \mathrm{L}$ was obtained in $1.0 \mathrm{M} \mathrm{HCl}$ compared to $76.29 \%$ in $0.5 \mathrm{M} \mathrm{H}_{2} \mathrm{SO}_{4}$, IE > $70 \%$ up to the immersion time of $72 \mathrm{~h}$ before decreasing to $61 \%$ at the end of the investigation in $0.5 \mathrm{M} \mathrm{H}_{2} \mathrm{SO}_{4}$.

The decrease in IE with immersion time has been attributed in similar studies to the desorption of the inhibitor species from the surface of the steel $[8,18,19]$. This phenomenon is characteristic of the physisorptive mechanism of adsorption of the inhibitor to the surface of the steel [18 - 21].

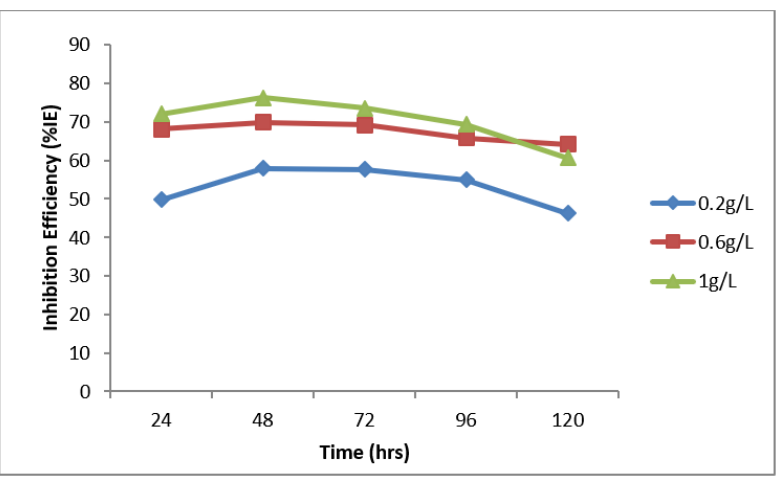

Figure 5. Inhibition efficiency as a function of time for the corrosion of mild steel in $0.5 \mathrm{M} \mathrm{H}_{2} \mathrm{SO}_{4}$.

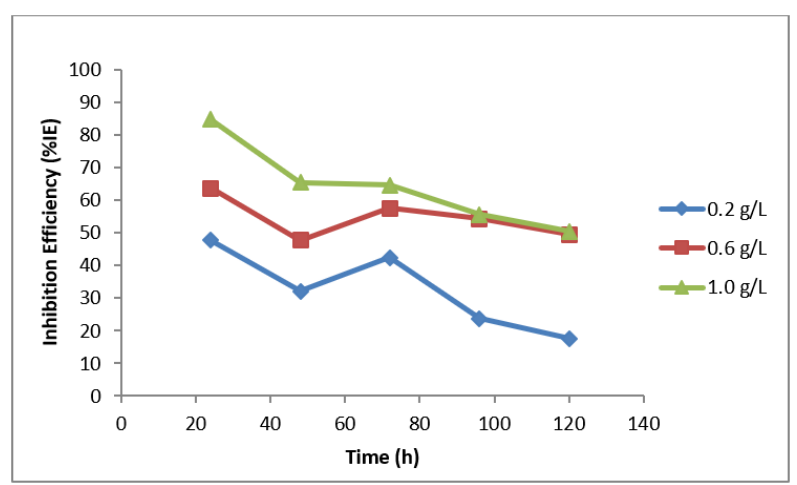

Figure 6. Inhibition efficiency as a function of time for the corrosion of mild steel in $1.0 \mathrm{M} \mathrm{HCl}$.

\subsection{Kinetics: rate constants $(k)$ and half-lives $\left(t_{1 / 2}\right)$}

The kinetics of the dissolution of the steel coupons in 0.5 $\mathrm{M} \mathrm{H}_{2} \mathrm{SO}_{4}$ and $1.0 \mathrm{M} \mathrm{HCl}$ solutions in the absence and presence of $0.2 \mathrm{~g} / \mathrm{L}, 0.6 \mathrm{~g} / \mathrm{L}$ and $1.0 \mathrm{~g} / \mathrm{L} \mathrm{CP}$ stem extract were investigated at $303 \mathrm{~K}$ by plotting $-\log$ (weight loss) versus time as presented in Figures 7 and 8 respectively. Linear plots with regression values that were close to unity were obtained indicating that the kinetics of the corrosion process aligned with the first order kinetics according to Eq. 5 [15, 22, 23]:

$$
-\log (w)=\frac{k_{1} t}{2.303}
$$

where $w$ is the weight loss of mild steel, $k_{1}$ is the rate constant for a first order reaction and $t$ is time in hours.

The half-life $\left(t_{1 / 2}\right)$ for the first order reaction is related to the rate constant as shown in Eq. 6 [15, 22, 23]:

$$
t_{1 / 2}=\frac{0.693}{k_{1}}
$$

Values of $k_{1}$ for the corrosion process and $t_{1 / 2}$ of mild steel in the absence and presence of the plant extract are presented on Tables 1 and 2. The rate constant is the tendency of the mild steel to corrode in the various test solutions [22]. It can be observed from Tables 1 and 2 that the values of $k_{1}$ for uninhibited test solutions were higher. The values of $k_{1}$ in the uninhibited systems however, decreased with increasing concentrations of $\mathrm{CP}$ stem extract revealing the inhibitive nature of the stem extract. This is corroborated by the increasing values of $t_{1 / 2}$ of mild steel in the presence of the stem extract. This implies that as the half-life increased, the corrosion rate 
of the steel decreased thereby extending the life span of the mild steel in both acid media.

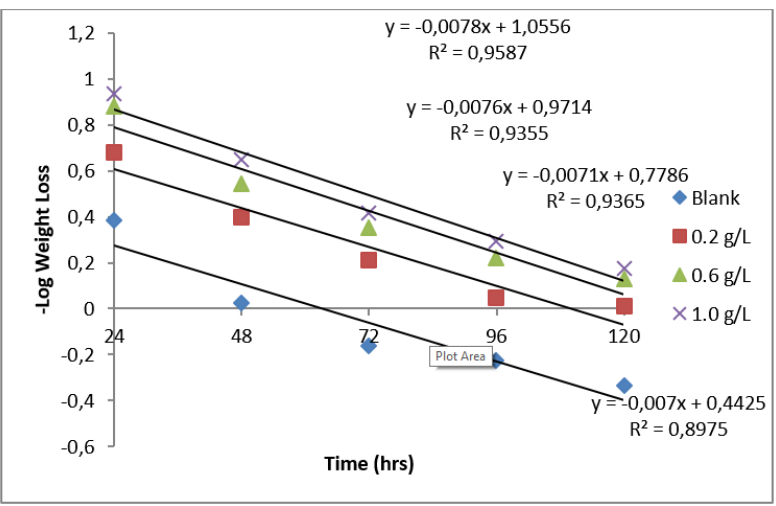

Figure 7. Plots of - $\log$ (weight loss) versus time for the corrosion of mild steel in the absence and presence of $\mathrm{CP}$ stem extract in $0.5 \mathrm{M} \mathrm{H}_{2} \mathrm{SO}_{4}$.

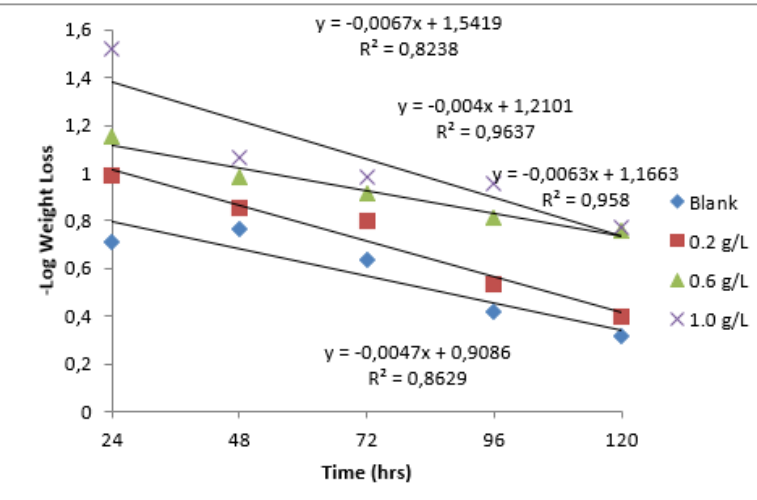

Figure 8. Plots of $-\log$ (weight loss) versus time for the corrosion of mild steel in the absence and presence of $\mathrm{CP}$ stem extract in $1.0 \mathrm{M} \mathrm{HCl}$.

Table 1. Kinetic parameters for the corrosion of mild steel in $0.5 \mathrm{M} \mathrm{H}_{2} \mathrm{SO}_{4}$ in the absence and presence of $\mathrm{CP}$ stem extract.

\begin{tabular}{cccc}
\hline System & $\begin{array}{c}\mathbf{k}_{\mathbf{1}}\left(\mathbf{1 0}^{-\mathbf{3}}\right) \\
{\left[\mathbf{h}^{-\mathbf{1}}\right]}\end{array}$ & $\begin{array}{c}\boldsymbol{t}_{\mathbf{1}} / \mathbf{2} \\
{[\mathbf{h}]}\end{array}$ & $\boldsymbol{R}^{\mathbf{2}}$ \\
\hline Blank & 5.4644 & 126.82 & 0.897 \\
$\mathbf{0 . 2} / \mathbf{L}$ & 2.8970 & 239.21 & 0.936 \\
$\mathbf{0 . 6 g} / \mathbf{L}$ & 1.6934 & 409.23 & 0.935 \\
$\mathbf{1 . 0} \mathbf{g} / \mathbf{L}$ & 1.5041 & 460.74 & 0.958 \\
\hline
\end{tabular}

Table 2. Kinetic parameters for the corrosion of mild steel in $1.0 \mathrm{M} \mathrm{HCl}$ in the absence and presence of $\mathrm{CP}$ stem extract.

\begin{tabular}{cccc}
\hline System & $\begin{array}{c}\mathbf{k}_{\mathbf{1}}\left(\mathbf{1 0}^{-\mathbf{3}}\right) \\
{\left[\boldsymbol{h}^{-\mathbf{1}}\right]}\end{array}$ & $\begin{array}{c}\boldsymbol{t}_{\mathbf{1}} / \mathbf{2} \\
{[\mathbf{h}]}\end{array}$ & $\boldsymbol{R}^{\mathbf{2}}$ \\
\hline Blank & 2.4337 & 284.75 & 0.862 \\
$\mathbf{0 . 2 g} / \mathbf{L}$ & 1.662 & 416.96 & 0.958 \\
$\mathbf{0 . 6 g} / \mathbf{L}$ & 1.151 & 601.87 & 0.963 \\
$\mathbf{1 . 0} \mathbf{g} / \mathbf{L}$ & 0.875 & 770.42 & 0.823 \\
\hline
\end{tabular}

\subsection{Temperature considerations and thermodynamics}

Thermodynamically, the average kinetic energy of reacting species in a system is a function of the temperature. The effect of temperature on the rate of corrosion of mild steel in uninhibited and inhibited solutions of $0.5 \mathrm{M} \mathrm{H}_{2} \mathrm{SO}_{4}$ and $1.0 \mathrm{M} \mathrm{HCl}$ at the temperature range of $303-333 \mathrm{~K}$ are presented in Figures
9 and 10 respectively. The plots revealed that the rates of corrosion of mild steel generally increased at higher temperature values both in the free acid solutions and in the presence of CP stem extract.

Reacting species become more energetic with a rise in temperature, this explains the increased rates of corrosion of the mild steel in both the uninhibited and inhibited test solutions at higher temperatures. This observation is corroborated by other researchers [16, 20, $24,25]$. However, the rate of corrosion of mild steel was relatively lower in the inhibited test solutions compared with the free acid solutions. Again, this signifies the inhibitive action of CP stem extract on the corrosion of mild steel in both acid media.

Figures 11 and 12 illustrate the trend of the inhibition of CP stem extract with a rise in temperature. The plots reflect decrease in inhibition efficiency of $\mathrm{CP}$ with temperature rise in both acid media. This lowering of inhibition efficiency values with increasing temperature has been reported by other scholars to be associated with physisorption [8, 19, 20].

Physisorption involves weak metal-inhibitor interactions which can be disrupted by any slight perturbation to the system. Such perturbations include the enhanced rates of hydrogen gas evolution at higher temperatures, which increasingly agitates the interface and also promotes dispersal of adsorbed inhibitor. The high temperature disruption of the system is sufficiently minimized at high extract concentration and the inhibiting effect is more or less stable [8].

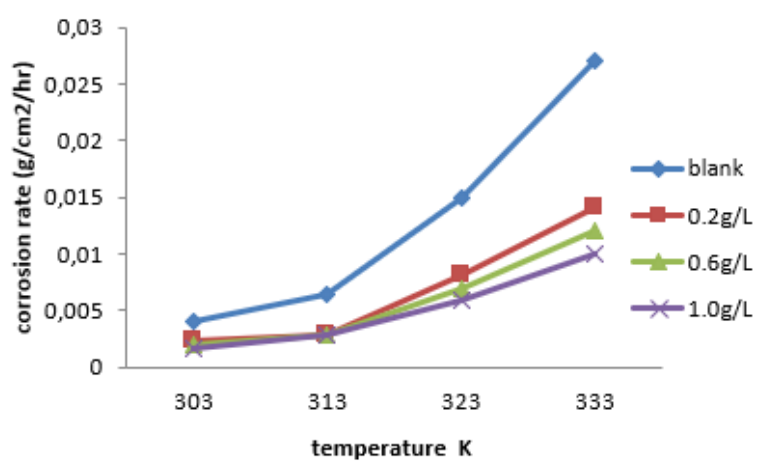

Figure 9. Corrosion rate of mild steel as a function of temperature in $0.5 \mathrm{M} \mathrm{H}_{2} \mathrm{SO}_{4}$ in the absence and presence of $\mathrm{CP}$ extract.

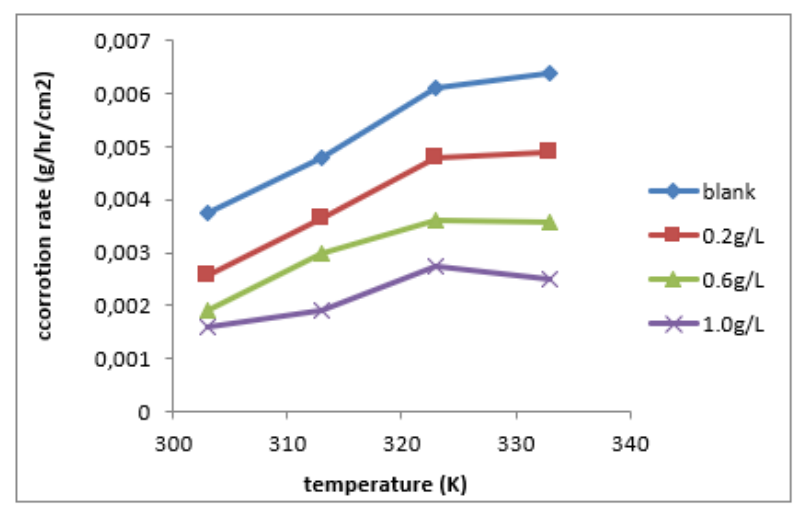

Figure 10. Corrosion rate of mild steel as a function of temperature in $1.0 \mathrm{M} \mathrm{HCl}$ in the absence and presence of $\mathrm{CP}$ extract. 


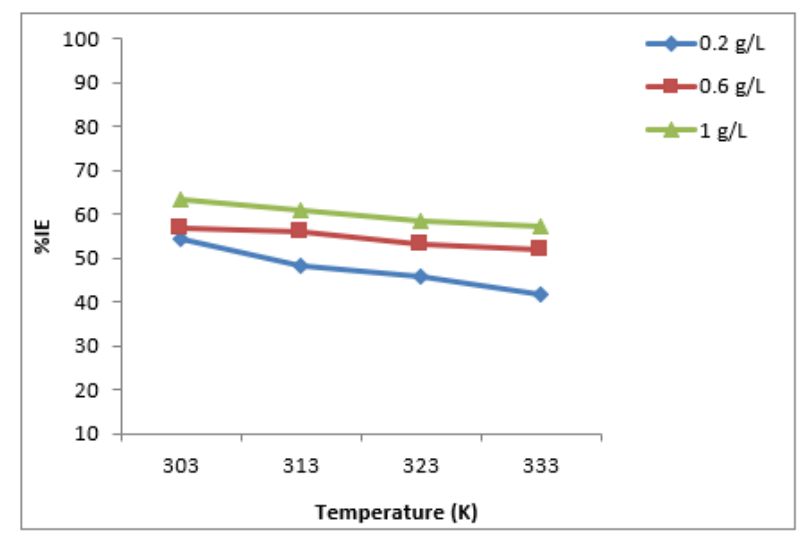

Figure 11. Inhibition efficiency of $\mathrm{CP}$ extract as a function of temperature in $0.5 \mathrm{M} \mathrm{H}_{2} \mathrm{SO}_{4}$.

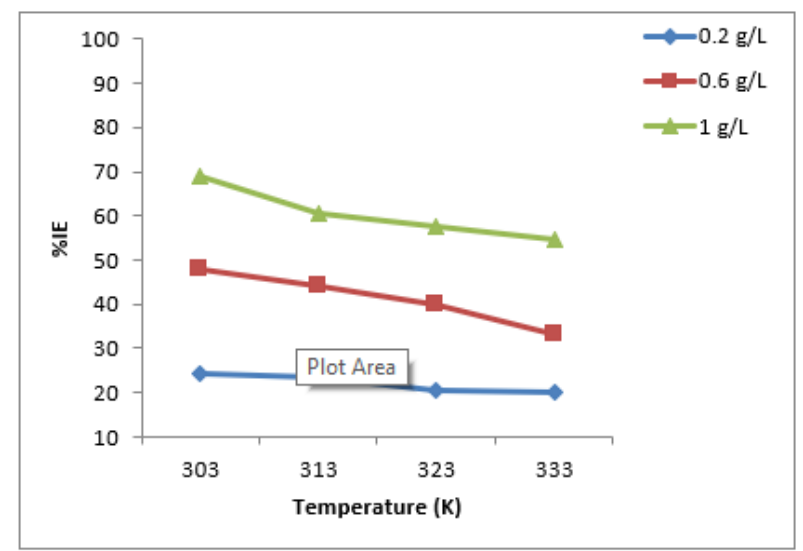

Figure 12. Inhibition efficiency of $\mathrm{CP}$ extract as a function of temperature in $1.0 \mathrm{M} \mathrm{HCl}$.

The relationship between the corrosion rate of mild steel in the various test solutions and temperature was evaluated using the Arrhenius equation (Eq. 7).

Taking the logarithm of both sides of Eq. 7, Eq. 8 is obtained.

$$
\begin{aligned}
C R & =A \exp ^{-E_{a} / R T} \\
\log C R & =\log A-\frac{E_{a}}{2.303 R T}
\end{aligned}
$$

where $C R$ is the rate of corrosion of the metal, $A$ is the Arrhenius or pre-exponential factor, $E_{a}$ is the apparent effective activation energy, $R$ is the universal gas constant, and $T$ is the absolute temperature of the system $(\mathrm{K})$. If the corrosion rates of the metal at two temperatures $T_{1}(303 \mathrm{~K})$ and $T_{2}(333 \mathrm{~K})$ are known, then Eq. 8 can be transformed into Eq. 9:

$$
\log \left(C R_{2} / C R_{1}\right)=E_{a} / 2.303 R\left(1 / T_{1}-1 / T_{2}\right)
$$

$E_{a}$ values obtained in the presence of CP stem extract were observed to be lower than that in the uninhibited solutions (Table 3) which support the mechanism of physical adsorption. For physical adsorption, it is expected that $E_{a}$ values should be less than 80.000 $\mathrm{kJ} \cdot \mathrm{mol}^{-1}[9,26]$.

Enthalpy $\left(\Delta H^{*}\right)$ and entropy $\left(\Delta S^{*}\right)$ of activation of the corrosion inhibition were evaluated using the Eyring $\mathrm{Eq}$ :

$$
\log C R / T=\left[\log (R / n h)+\Delta S^{*} / 2.303 R\right]-\Delta H^{*} / 2.303 R T(10)
$$

where $C R$ is the corrosion rate at temperature T, $R$ is the molar gas constant, $n$ is Avogadro's constant $6.0225 \times$ $10^{23}$ and $h$ is the Planck's constant $\left(6.6261 \times 10^{-34} \mathrm{JS}\right)$. A plot of $\log C R / T$ versus $1 / T$ is a straight line graph with a slope of $\left(-\Delta H^{*} / 2.303 R\right)$ and an intercept of $\left[\log (R / n h)+\Delta S^{*} / 2.303 R\right][9,16,20,21]$.

Table 3 shows that the enthalpies of activation were all positive which reveals the endothermic nature of the dissolution process of the mild steel. Entropies of activation were all negative. Negative values of $\Delta S^{*}$ have been reported by Refat and Ishaq to represent the association mechanism of the corrosion process whereby a decrease in disorder takes place on going from the

\begin{tabular}{|c|c|c|c|}
\hline System & $\begin{array}{c}\mathrm{E}_{\mathrm{a}} \\
{\left[\mathrm{kJ} \mathrm{mol}^{-1}\right]}\end{array}$ & $\begin{array}{c}\Delta \mathrm{H}_{\text {ads }}^{\mathrm{o}} \\
{\left[\mathrm{kJ} \mathrm{mol}^{-1}\right]}\end{array}$ & $\begin{array}{c}\Delta \mathrm{S}_{\text {ads }}^{\mathrm{o}} \\
{\left[\mathrm{kJ} \mathrm{mol}^{-1}\right]}\end{array}$ \\
\hline \multicolumn{4}{|c|}{$0.5 \mathrm{M} \mathrm{H}_{2} \mathrm{SO}_{4}$} \\
\hline Blank & 49.46 & 48.44 & -16.68 \\
\hline $0.2 \mathrm{~g} / \mathrm{L}$ & 50.49 & 50.28 & -15.84 \\
\hline $0.6 \mathrm{~g} / \mathrm{L}$ & 50.36 & 50.3 & -15.43 \\
\hline $1.0 \mathrm{~g} / \mathrm{L}$ & 53.23 & 51.03 & -15.13 \\
\hline \multicolumn{4}{|c|}{$1.0 \mathrm{M} \mathrm{HCl}$} \\
\hline Blank & 12.72 & 50.68 & -212.09 \\
\hline $0.2 \mathrm{~g} / \mathrm{L}$ & 14.81 & 51.66 & -203.32 \\
\hline $0.6 \mathrm{~g} / \mathrm{L}$ & 17.41 & 61.02 & -198.24 \\
\hline $1.0 \mathrm{~g} / \mathrm{L}$ & 17.77 & 224.6 & -154.67 \\
\hline
\end{tabular}
reactants to the activated complex $[21,26]$.

Table 3. Thermodynamic parameters for the adsorption $C P$ stem extract on mild steel surface.

\subsection{Adsorption}

The adsorption mechanisms of CP stem extract on the steel surface in the different acid media were investigated by fitting surface coverage $(\theta)$ values derived from weight loss data into various adsorption isotherms. Langmuir, Freundlich and Temkin isotherms (Figures 13, 14 and 15 respectively) were found to best describe the adsorption of CP stem extract on the steel surface with all the plots having linear slopes and regression coefficients $\left(R^{2}\right)$ values close to unity $[8,9,26]$.

The adsorption equilibrium constant, $K_{a d s}$ is related to the standard free energy of adsorption, $\Delta G_{a d s}^{\circ}$ by Eq. 11:

$$
\Delta G_{a d s}=-2.303 \times R T \log \left(55.5 K_{a d s}\right)
$$

Calculated values of $K_{a d s}$ and $\Delta G_{a d s}^{\circ}$ are presented on Table 4 . The values of $\Delta G_{a d s}^{\circ}$ were negative and less than $-40 \mathrm{~kJ} \mathrm{~mol}^{-1}$ for all the three adsorption models. This implies that the adsorption of CP stem extract on the steel surface was spontaneous and physisorptive [20, 21, 24, 26]. 


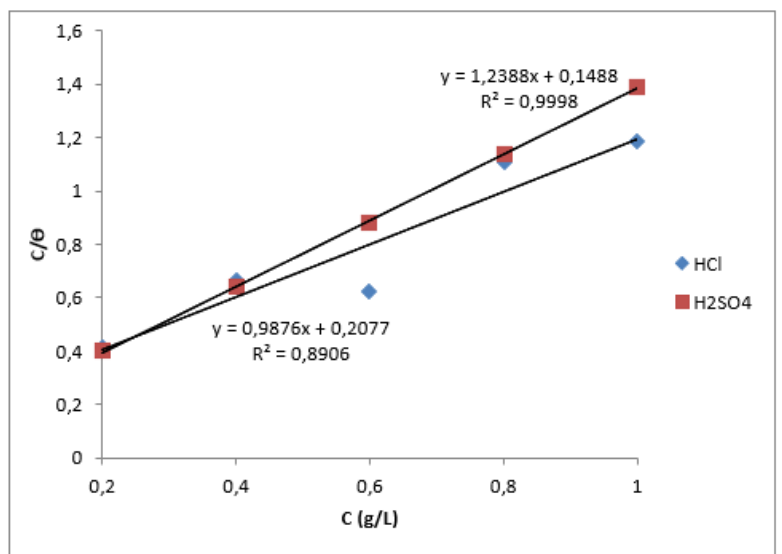

Figure 13. Langmuir isotherm for the adsorption of CP stem extract on the steel surface.

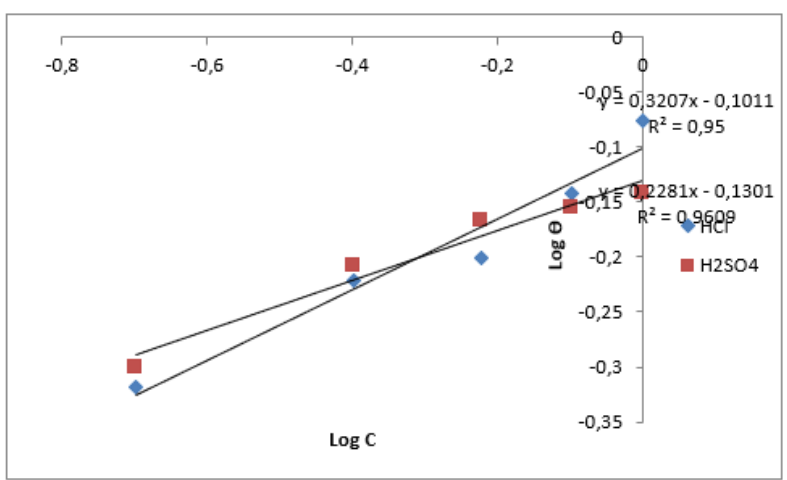

Figure 14. Freundlich isotherm for the adsorption of CP stem extract on the steel surface.

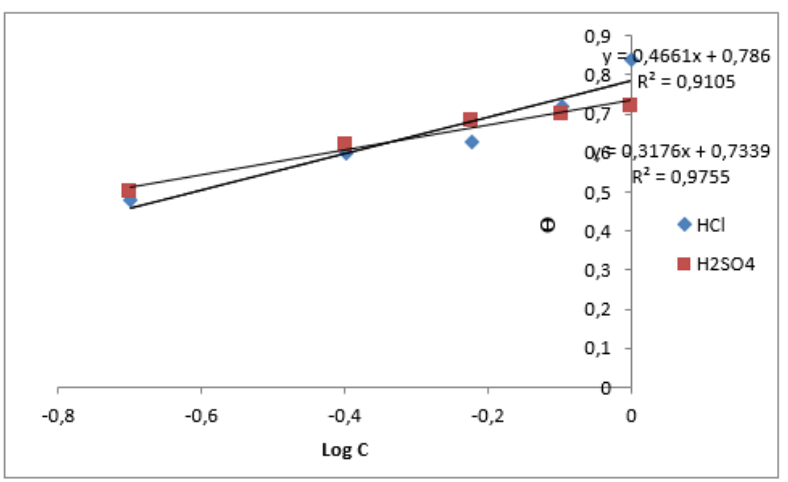

Figure 15. Temkin isotherm for the adsorption of CP stem extract on the steel surface.

Table 4. Adsorption parameters of $\mathrm{CP}$ stem extract on mild steel surface in $0.5 \mathrm{M} \mathrm{H}_{2} \mathrm{SO}_{4}$ and $1.0 \mathrm{M} \mathrm{HCl}$ respectively.

\begin{tabular}{|c|c|c|c|}
\hline Isotherm & $k_{\text {ads }}$ & $R^{2}$ & $\begin{array}{c}\Delta \boldsymbol{G}_{\text {ads }} \\
{\left[\mathrm{kJ} \mathrm{mol}^{-1}\right]}\end{array}$ \\
\hline \multicolumn{4}{|l|}{ Langmuir } \\
\hline $\mathrm{HCl}$ & 4.831 & 0.890 & -14.09 \\
\hline $\mathrm{H}_{2} \mathrm{SO}_{4}$ & 6.757 & 0.999 & -14.93 \\
\hline \multicolumn{4}{|l|}{ Freundlich } \\
\hline HCl & 1.262 & 0.950 & -10.70 \\
\hline $\mathrm{H}_{2} \mathrm{SO}_{4}$ & 1.690 & 0.960 & -11.44 \\
\hline \multicolumn{4}{|l|}{ Temkin } \\
\hline $\mathrm{HCl}$ & 48.61 & 0.910 & -19.91 \\
\hline $\mathrm{H}_{2} \mathrm{SO}_{4}$ & 205.12 & 0.986 & -23.53 \\
\hline
\end{tabular}

\section{Conclusion}

Findings from this study revealed that Cissus populnea stem extract inhibited the corrosion of mild steel in
$\mathrm{H}_{2} \mathrm{SO}_{4} 0.5 \mathrm{M}$ and $1.0 \mathrm{M} \mathrm{HCl}$ respectively. The inhibition process was concentration dependent. The kinetics of the reaction aligned with a first order type. The values of $k_{1}$ decreased with increasing $\mathrm{CP}$ concentrations while $t_{1 / 2}$ increased signifying the inhibitive effect of CP on the corrosion process in both acid media. Activation and standard free energy values of adsorption obtained showed that Cissus populnea extract adsorbed on the steel surface through physical interactions, and that the adsorption process was spontaneous. The positive values of enthalpy obtained in the study showed the endothermic nature of the adsorption process while the negative values of entropy reveal the association mechanism of the corrosion inhibition process whereby a decrease in disorder takes place on going from the reactants to the activated complex. Langmuir, Freundlich and Temkin isotherm models best described the adsorption mechanism of the stem extract on the steel surface.

\section{Conflict of interest}

The authors declare no conflict of interest.

\section{References}

[1]. B.E.A. Rani, B.B.J. Basu, Green inhibitors for corrosion protection of metals and alloys: an overview, International Journal of corrosion 2012, article ID: 380217. Doi:10.1155/2012/380217

[2]. M.H. Hussin, M.J. Kassim, N.N. Razali, N.H. Dahon, D. Nasshorudin, The effect Tinospora crispa extracts as a natural mild steel corrosion inhibitor in $1 \mathrm{M} \mathrm{HCl}$ solution, Arabian Journal of Chemistry 9 (2016) S616 - S624.

[3]. H. Ashassi-sorkhabi, B. Shaabani, B. Aligholipour, D. Seifzadeh, The effect of some Schiff bases on the corrosion of aluminium in $\mathrm{HCl}$ solution, Applied Surface Science 252 (2006) 4039-4047.

[4]. E.H. El Ashry, A. El Nemir, S.A. Esawy, S. Ragab, Corrosion inhibitors. Part II: Quantum chemical studies on the corrosion inhibitions of steel in acidic medium by some triazole, oxadiazole and thiadiazole derivatives, Electrochimica Acta 51 (2006) $3957-3968$.

[5]. N.O. Eddy, H. Momoh-Yahaya, E.E. Oguzie, Theoretical and experimental studies on the corrosion inhibition potentials of some purines for aluminium in $0.1 \mathrm{M} \mathrm{HCl}$, Journal of Advanced Research 6 (2015) 203 - 217.

[6]. N.O. Eddy, Inhibitive and adsorption properties of ethanol extract of Colocasia esculenta leaves for the corrosion of mild steel in $\mathrm{H}_{2} \mathrm{SO}_{4}$, International Journal of Physical Sciences 4 (2009) 165 - 171.

[7]. A.O. James, O. Akaranta, The inhibition of corrosion of zinc in $2.0 \mathrm{M}$ hydrochloric acid solution with acetone extract of red onion skin, African Journal of Pure and Applied Chemistry 3 (2009) 212 - 217.

[8]. E.E. Oguzie, I.M. Mejeha, M.C. Nwandu, K.B. Okeoma, L.A. Nnanna, M.A. Chidiebere, F.C. Eze, Experimental and theoretical assessment of the inhibiting action of Aspilia africana extract on corrosion of aluminium alloy AA3003 in 
hydrochloric acid, Journal of Material Science 47 (2012) 2559 - 2572.

[9]. H.F. Chahul, A.M. Ayuba, S. Nyior, Adsorptive, kinetic, thermodynamic and inhibitive properties of Cissus populnea stem extraction the corrosion of aluminium in $\mathrm{HCl}$, ChemSearch Journal 1 (2015) $20-30$.

[10]. E.E. Oguzie, C.K. Enenebeaku, C.O. Akalezi, S.C. Okoro, A.A. Ayuk, E.N. Ejike, Adsorption and corrosion inhibiting effect of Dacryodis edulis extract on low carbon steel corrosion in acidic media, Journal of Colloid and Interface Science 349 (2010) 283 - 292.

[11]. H.F. Chahul, G.I. Ndukwe, D.O. Ogwu, A thermometric study on the kinetics of the acid dissolution of aluminium in the presence of Napoleonaea imperialis seeds extract and iodide ions, Ovidius University Annals of Chemistry 29 (2018) 103 - 109.

[12]. A.I. Onen, J. Buba, Ficuspolita (bush fig) leaves extract as corrosion inhibitor of aluminium in alkaline medium, Journal of Chemical Society of Nigeria 43 (2018) 93 - 102.

[13]. M.O. Soladoye, E.C. Chukwuma, Phytochemical analysis of the stem and root of Cissus populnea (vitaceae) - An important medicinal plant in central Nigeria, Phytologia Balcanica 18 (2012) 149 - 153.

[14]. S.F. Akomolafe, O. Ganiyu, A.A. Akindahunsi, A.J. Akinyemi, O.G. Tade, Inhibitory effect of aqueous extract of stem bark of Cissus populnea on ferrous sulphate- and sodium nitroprusside-induced oxidative stress in rat's testes in vitro, ISRN Pharmacology 2013, article ID 130989. Doi:10.1155/2013/130989

[15]. O.K. Abiola A.O. James, The effects of aloe vera extract on corrosion and kinetics of corrosion process of zinc in $\mathrm{HCl}$ solution, Corrosion Science 52 (2010) $661-664$.

[16]. E.F. Olasehinde, S.J. Olusegun, A.S. Adesina, S.A. Omogbehin, H. Momoh-Yahaya, Inhibitory action of Nicotiana tabacum extracts on the corrosion of mild steel in $\mathrm{HCl}$ : Adsorption and thermodynamics study, Nature and Science 10 (2012) 21 - 34.

[17]. E.E. Oguzie, Y. Li, F.H. Wang, Corrosion inhibition and adsorption behaviour of methionine on mild steel in sulphuric acid and synergistic effect of iodide ions, Journal of Colloid Interface Science 310 (2007) 90 - 98.
[18]. I.B. Obot, N.O. Obi-Egbedi, Fluconazole as an inhibitor for aluminium corrosion in $0.1 \mathrm{M} \mathrm{HCl}$, Colloids and Surfaces A: Physicochemical and Engineering Aspects 330 (2008) 207 - 212.

[19]. I.B. Obot, N.O. Obi-Egbedi, Adsorption properties and inhibition of mild steel corrosion in sulphuric acid solution by ketoconazole: Experimental and theoretical investigation, Corrosion Science 52 (2010) 198 - 204.

[20]. K.S. Sudhish, E.E. Eno, Corrosion inhibition, adsorption behaviour and thermodynamic properties of streptomycin on mild steel in hydrochloric acid medium, International Journal Electrochemical Science 6 (2011) 3277 - 3291.

[21]. M.H. Refat, A.Z. Ishaq, Kinetics of corrosion inhibition of aluminium in acidic media by watersoluble natural polymeric pectates as anionic polyelectrolyte inhibitors, Materials 6 (2013) 2436 $-2451$.

[22]. J.A. Undiandeye, T.J. Chior, A. Mohammed, J.C. Offurum, Kinetics of the corrosion of mild steel in petroleum-water mixture using ethyl ester of lard as inhibitor, African Journal of Pure and Applied Chemistry 8 (2014) 60 - 67.

[23]. N.C. Ngobiri, K. Okorosaye-Orubite, Adsorption and corrosion inhibition characteristics of two medicinal molecules, Chemistry International 2 (2017) 185 - 194

[24]. M.A. Quraishi, A.K. Singh, Piroxicam: A novel corrosion inhibitor for mild steel corrosion in $\mathrm{HCl}$ acid solution, Journal of Materials and Environmental Science 1 (2010) 101 - 110.

[25]. H. Momoh-Yahaya, N.O. Eddy, J.F. Iyun, C.E. Gimba and E.E. Oguzie, Experimental investigation of the inhibiting action of adenine on the corrosion of mild steel in acidic environments, Journal of Material Science Research 2 (2013) 59 - 74.

[26]. H.F. Chahul, G.I. Ndukwe, S.T. Abawua, Corrosion inhibition studies of mild steel with stem bark extract of Maranthes polyandra (benth.) prance, Journal of Chemical Society of Nigeria 42 (2017) $55-61$.

Received: 31.01 .2019

Received in revised form: 03.03.2019

Accepted: 05.03.2019 